\title{
Isotopic Labeling of Red Cabbage Anthocyanins with Atmospheric ${ }^{13} \mathrm{CO}_{2}$
}

\author{
Craig S. Charron, Steven J. Britz, Roman M. Mirecki, Dawn J. Harrison, \\ Beverly A. Clevidence, and Janet A. Novotny ${ }^{1}$ \\ Food Components and Health Laboratory, Beltsville Human Nutrition Research Center, \\ ARS/U.S. Department of Agriculture, 10300 Baltimore Ave., Beltsville MD 20705
}

\begin{abstract}
AdDitional INDEX words. Brassica oleracea, stable isotopes, metabolism
Abstract. Isotopic labeling of plants provides a unique opportunity for understanding metabolic processes. A significant challenge of isotopic labeling during plant growth is that isotopes must be administered without disrupting plant development and at sufficient levels for mass spectral analysis. We describe a system for isotopic labeling of leafy vegetables with ${ }^{13} \mathrm{C}$ and demonstrate successful incorporation of ${ }^{13} \mathrm{C}$ into anthocyanins of preheading red cabbage (Brassica oleracea L. var. capitata L.). 'Super Red' red cabbage seedlings were grown for 34 days in an airtight acrylic labeling chamber supplied with ${ }^{13} \mathrm{CO}_{2}$ to maintain $400 \mu \mathrm{L} \cdot \mathrm{L}^{-1}$. Nutrient solution was delivered hydroponically without allowing infusion of natural $\mathrm{CO}_{2}$ into the labeling chamber. Plants were initially grown at $22{ }^{\circ} \mathrm{C} \pm 1{ }^{\circ} \mathrm{C}$ in constant light of $228 \mu \mathrm{mol} \cdot \mathrm{m}^{-2} \cdot \mathrm{s}^{-1}$. Upon canopy closure, anthocyanin development was promoted by reducing the nutrient solution concentration and reducing the temperature to $10.5{ }^{\circ} \mathrm{C} \pm 1.5^{\circ} \mathrm{C}$. Total shoot fresh weight (FW) was $1556 \mathrm{~g}$ and root FW was $491 \mathrm{~g}$ at harvest. Analysis of red cabbage shoot tissue by high-performance liquid chromatography/tandem mass spectrometry indicated the presence of 37 anthocyanins, of which 14 are reported here for the first time. Mass shifts representing ${ }^{13} \mathrm{C}$ incorporation into anthocyanins were evident in mass spectra of anthocyanins from labeled tissue and demonstrate successful isotopic labeling.
\end{abstract}

Isotopic labeling of plants is a powerful strategy for studying metabolic processes. Plant compounds that have incorporated isotopic labels are distinguishable from their unlabeled analogs by mass spectrometry, and therefore can be traced in complex biochemical matrices. In plant science, isotopic labeling has been used to study carbohydrate biosynthesis, nitrogen metabolism, and photosynthate partitioning (Kollman et al., 1973; Schiltz et al., 2005; Yamagata et al., 1987). Isotopic labeling of plants consumed as foods has also provided unique opportunities for understanding human nutrient metabolism (Grusak, 1997; Novotny et al., 2003).

Isotopes can be introduced into plants through roots, stems, or leaves. Root uptake of nitrogen-15 $\left({ }^{15} \mathrm{~N}\right)$-enriched ammonium nitrate or urea has been used to characterize nitrogen distribution and remobilization in pea (Pisum sativum L.), orange (Citrus sinensis L.), and spring wheat (Triticum aestivum L.; Ma et al., 2006; Menino et al., 2007; Schiltz et al., 2005). Stem injection of isotopically labeled sulfur-35 $\left({ }^{35} \mathrm{~S}\right)$ into hard red winter wheat was used to study grain protein content (Kahlon and Chow, 1989). Isotopes may be introduced through leaves by means of photosynthetic fixation of labeled $\mathrm{CO}_{2}$. Using a pulse-chase technique in which Arabidopsis thaliana (L.) Heynh was exposed to ${ }^{14} \mathrm{CO}_{2}$ for $10 \mathrm{~min}$, followed by exposure to natural $\mathrm{CO}_{2}$ for another $10 \mathrm{~min}$, Sun et al. (1999) measured carbon partitioning into starch and sucrose. Because of safety concerns with radioisotopes, ${ }^{13} \mathrm{CO}_{2}$ is often selected for metabolic studies. Partitioning and utilization of photosynthate in soybean [Glycine max (L.) Merr.] was evaluated by periodic exposure to ${ }^{13} \mathrm{CO}_{2}$ in a labeling chamber and harvests at different growth stages (Yamagata et al., 1987). Carbon losses in french bean (Phaseolus vulgaris L.) leaves during dark respiration were studied by isolating an illuminated attached

Received for publication 19 Dec. 2007. Accepted for publication 13 Mar. 2008. ${ }^{1}$ Corresponding author. E-mail: janet.novotny@ars.usda.gov. leaflet in a ${ }^{13} \mathrm{CO}_{2}$-enriched chamber for $10 \mathrm{~h}$, followed by isolation in a respiration chamber in darkness (Nogués et al., 2004). A similar technique was developed to measure carbon fluxes in leaflets of drought-stressed tomato (Solanum lycopersicum L.; Haupt-Herting et al., 2001). Whole-plant labeling with atmospheric ${ }^{13} \mathrm{CO}_{2}$ has been performed on larch (Larix Mill.) in a canopy-scale open air system over $5 \mathrm{~d}$ (Talhelm et al., 2007). Although this system was simpler than techniques using chambers or other enclosures, and ${ }^{13} \mathrm{C}$-enriched foliar respiration was detected, leaf incorporation of ${ }^{13} \mathrm{C}$ was not significantly different from control trees.

Successful atmospheric labeling with ${ }^{13} \mathrm{CO}_{2}$ poses a number of challenges. Uniform labeling is highly advantageous because the resulting labeled molecules exist as a predominant isotopomer, thus improving mass spectral detection and structure identification. To ensure uniform labeling, plants must be housed in an airtight labeling chamber, and the seal cannot be broken for irrigation. An organic growth medium may not be used because microbial metabolism of carbon substrates will dilute the ${ }^{13} \mathrm{CO}_{2}$ with respired natural $\mathrm{CO}_{2}$.

In this article, we describe a study to label organic compounds in leafy vegetables with ${ }^{13} \mathrm{C}$ by cultivation in a controlled environment containing atmospheric ${ }^{13} \mathrm{CO}_{2}$ and to characterize labeled compounds by high-performance liquid chromatography-tandem mass spectrometry (HPLC-MS/MS). Due to our particular interest in anthocyanins, we have chosen red cabbage (Brassica oleracea var. capitata) as the crop for labeling, and we have used anthocyanin labeling as a primary measure of success.

\section{Materials and Methods}

'Super Red' red cabbage was grown in 10.2-cm-diameter pots in an airtight labeling chamber supplied with ${ }^{13} \mathrm{CO}_{2}$ starting from seedling stage ( $9 \mathrm{~d}$ after sowing; first true leaves 
visible in $>50 \%$ of seedlings) and ending at harvest after $34 \mathrm{~d}$. The labeling chamber was placed on a stainless steel wire rolling cart (Metro, Wilkes Barre, PA) located in a walk-in M28 growth chamber (Environmental Growth Chambers, Chagrin Falls, OH).

LABELING CHAMBER. The labeling chamber consisted of two sections constructed of 6.4-mm-thick clear ultraviolet lighttransparent acrylic sheet (Fig. 1). The upper section was a box ( $1.03 \mathrm{~m}$ long $\times 0.75 \mathrm{~m}$ wide $\times 0.84 \mathrm{~m}$ high) that was set on a base $(1.10 \mathrm{~m}$ long $\times 0.82 \mathrm{~m}$ wide). The bottom edge of this box was immersed in a water-filled trough, thereby forming an airtight seal. ${ }^{13} \mathrm{CO}_{2}$ concentration in the labeling chamber was measured by a WMA-4 IR gas analyzer (IRGA; PP Systems, Amesbury, MA) retrofitted with an erasable programmable read-only memory chip (V1.44 SP1; PP Systems) that allowed the IRGA to be calibrated with ${ }^{13} \mathrm{CO}_{2}$. A temperature and relative humidity probe (model CS500; Campbell Scientific, Logan, UT) in a radiation shield (model 41003; Campbell Scientific) was located in the labeling chamber $15 \mathrm{~cm}$ above the surface of the acrylic base. An axial fan (model 4C549A; Dayton Electric, Niles, IL) was positioned centrally on the upper surface of the labeling chamber to promote air mixing and uniform heat distribution. Six ports with $0.64-\mathrm{cm}$ bulkhead fittings were located next to the axial fan to accommodate the following: 1) temperature/relative humidity probe signal leads, 2) axial fan power cord, 3) ${ }^{13} \mathrm{CO}_{2}$ supply tube, 4) IRGA inlet sampling tube, 5) IRGA return flow tube, and 6) tube to barometer (model PTB101B; Vaisala, Woburn, MA).

Additional cooling capacity and relative humidity control were achieved by a heat exchanger consisting of four $0.55-\mathrm{m}$ lengths of finned tubing $(2.31 \mathrm{~cm}$ o.d.) connected in series and attached to an inside end wall of the labeling chamber. Water chilled by a refrigerated bath (model RTE-8; Neslab, Newington, $\mathrm{NH}$ ) was supplied to the heat exchanger through braided vinyl tubing $(1.6 \mathrm{~cm}$ o.d. $\times 1.0 \mathrm{~cm}$ i.d.) connected to a $1.0-\mathrm{cm}$ hose barb adapter in a side wall of the labeling chamber. The air temperature inside the labeling chamber was controlled by the temperature of the water passing through the heat exchanger and by the air temperature outside of the labeling chamber. Condensate from the heat exchanger drained into the water trough. The water level in the trough was periodically reduced by siphoning to prevent flow over the lip of the trough.

${ }^{13} \mathrm{CO}_{2}$ CONTROL AND ENVIRONMENTAL DATa RECORDING. Air from the labeling chamber flowed at $0.4 \mathrm{~L} \cdot \mathrm{min}^{-1}$ through Bev-a-

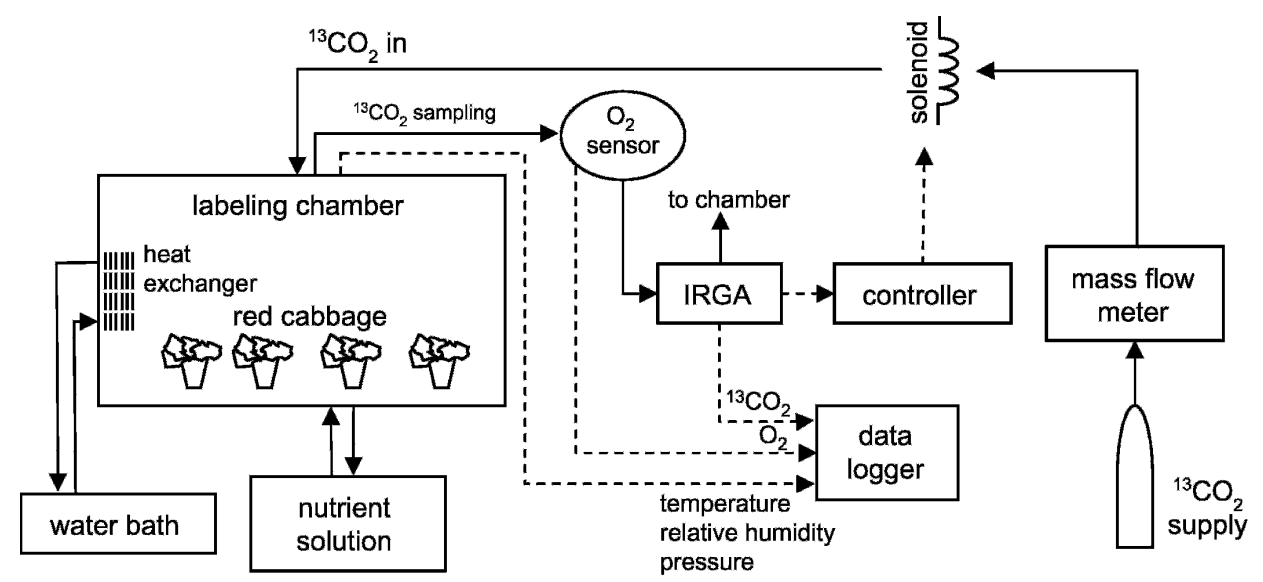

Fig. 1. Schematic of system for ${ }^{13} \mathrm{C}$ labeling of hydroponically grown red cabbage. Arrows represent data lines (- -) and gas or liquid flow (-); IRGA = infrared gas analyzer.
Line IV tubing $(64 \mathrm{~mm}$ o.d. $\times 32 \mathrm{~mm}$ i.d.; Thermoplastic Processes, Stirling, NJ) to an in-line oxygen sensor (model 02SF; Apogee Instruments, Logan, UT), then to the IRGA, which monitored ${ }^{13} \mathrm{CO}_{2}$ concentration, and then returned to the labeling chamber. The IRGA was connected to a proportional-integral-derivative controller (model CN77322; Omega Engineering, Stamford, CT). When the ${ }^{13} \mathrm{CO}_{2}$ concentration fell below $390 \mu \mathrm{L} \cdot \mathrm{L}^{-1}$, the proportional-integral-derivative controller activated a normally closed solenoid (model EW-98165-60; Asco Valve, Florham Park, NJ), thereby supplying ${ }^{13} \mathrm{CO}_{2}$ to the labeling chamber. The ${ }^{13} \mathrm{CO}_{2}\left(99.3\right.$ atom $\%{ }^{13} \mathrm{C}$; Isotec, Miamisburg, $\mathrm{OH}$ ) flowed from the source tank through Mazzerpur 95 tubing $(64 \mathrm{~mm}$ o.d. $\times 32 \mathrm{~mm}$ i.d.; Mazzer Industries, Rochester, NY) to a mass flow meter (Cole-Parmer Instrument, Vernon Hills, IL), through the solenoid, and into the labeling chamber. Although the solenoid returned to its normally closed state when the IRGA measured $400 \mu \mathrm{L} \cdot \mathrm{L}^{-1}{ }^{13} \mathrm{CO}_{2}$, the ${ }^{13} \mathrm{CO}_{2}$ concentration in the labeling chamber typically stabilized around $430 \mu \mathrm{L} \cdot \mathrm{L}^{-1}$ after $2 \mathrm{~min}$ of air mixing.

A data logger (model CR23X; Campbell Scientific) recorded 5-min and 1-h mean, maximum and minimum values of ${ }^{13} \mathrm{CO}_{2}$ concentration, $\mathrm{O}_{2}$ concentration, air temperature, relative humidity, barometric pressure, and the temperature of the heat exchanger in the labeling chamber. Data for the atmospheric pressure outside of the labeling chamber were obtained from the Beltsville Agricultural Research Center in Beltsville, MD.

Nutrient Delivery SYSTEM. Plants were subirrigated daily with a complete nutrient solution that contained $14.5 \mathrm{mmol} \cdot \mathrm{L}^{-1}$ of nitrogen at full strength (Robinson, 1984). A reservoir holding $60.5 \mathrm{~L}$ of solution was located under the labeling chamber. For 10 min each day, a fountain pump (model PU250/ PP-399; Hydrofarm, Petaluma, CA) pumped solution through clear vinyl tubing $(1.3 \mathrm{~cm}$ o.d. $\times 1.0 \mathrm{~cm}$ i.d. $)$ through the base of the labeling chamber. Nutrient solution simultaneously returned to the reservoir by gravity flow through separate vinyl tubing of the same size. The peak depth of the solution in the base of the labeling chamber was $4.0 \mathrm{~cm}$ and from the time the pump was turned off, 25 min elapsed before all of the solution drained into the reservoir. Gas exchange between the labeling chamber and the outside air was prevented by the continuous presence of nutrient solution in the vinyl tubing.

Experimental PRotocol. To minimize $\mathrm{CO}_{2}$ evolution by microbial metabolism of carbon substrates, an inorganic growth medium was selected for red cabbage plants. The inside bottoms of 28 10.2-cm-diameter pots were fitted with sections of window screen to prevent loss of growth medium during drainage. Thirty grams of Turface MVP (Profile Products, Buffalo Grove, IL) was placed on the screen, followed by sufficient Greens Grade (Profile Products) to fill each pot to within $1.5 \mathrm{~cm}$ of the top. Turface MVP and Greens Grade are calcined clay products. Four 'Super Red' red cabbage seeds were planted in each pot, and all pots were placed in a growth chamber at $22{ }^{\circ} \mathrm{C} \pm 1{ }^{\circ} \mathrm{C}$. Constant light was supplied from fluorescent lamps and the photosynthetic photon flux $(P P F)$ was $385 \mu \mathrm{mol} \cdot \mathrm{m}^{-2} \cdot \mathrm{s}^{-1}$ 
at the surface of the growth medium $(10.2 \mathrm{~cm}$ above bench top).

After $9 \mathrm{~d}$, a single seedling was selected for uniformity and vigor in each pot, and the remaining seedlings were cut at the level of the growth medium and shoots were removed. The pots were placed in the labeling chamber and distributed evenly, and the chamber was sealed. To reduce the concentration of natural unlabeled $\mathrm{CO}_{2}$, the labeling chamber was flushed with nitrogen until the IRGA read $154 \mu \mathrm{L} \cdot \mathrm{L}^{-1}$. The IRGA had been calibrated with ${ }^{13} \mathrm{CO}_{2}$ and was about four times more sensitive to natural $\mathrm{CO}_{2}$ than ${ }^{13} \mathrm{CO}_{2}$. Therefore, it was estimated that the actual natural $\mathrm{CO}_{2}$ concentration was $40 \mu \mathrm{L} \cdot \mathrm{L}^{-1}$. The solenoid was activated and $292 \mathrm{~cm}^{3}$ (standard temperature and pressure) of ${ }^{13} \mathrm{CO}_{2}$ was injected into the labeling chamber, resulting in a $\mathrm{CO}_{2}$ (including ${ }^{12} \mathrm{C}$ and ${ }^{13} \mathrm{C}$ ) reading of $519 \mu \mathrm{L} \cdot \mathrm{L}^{-1}$. After correcting for the increased IRGA response to natural $\mathrm{CO}_{2}$, the actual $\mathrm{CO}_{2}\left({ }^{12} \mathrm{C}\right.$ and $\left.{ }^{13} \mathrm{C}\right)$ concentration was calculated to be 405 $\mu \mathrm{L} \cdot \mathrm{L}^{-1}$ (IRGA final reading - IRGA initial reading $+40 \mu \mathrm{L} \cdot \mathrm{L}^{-1}$ of natural $\mathrm{CO}_{2}$ ).

Plants were grown in constant light supplied by eight $400-\mathrm{W}$ metal halide lamps (model MS400/HOR; Sylvania, Danvers, MA) of the walk-in growth chamber. The mean $P P F$ measured at five locations $10.2 \mathrm{~cm}$ above the base of the labeling chamber was $228 \mu \mathrm{mol} \cdot \mathrm{m}^{-2} \cdot \mathrm{s}^{-1}$.

Temperature and nutrient fertility were chosen to promote anthocyanin development during red cabbage growth. The temperature in the labeling chamber was maintained at $22.0{ }^{\circ} \mathrm{C} \pm$ $0.5{ }^{\circ} \mathrm{C}$ for $26 \mathrm{~d}$ by setting the walk-in growth chamber temperature at $25.0{ }^{\circ} \mathrm{C}$ and varying the water bath temperature from $8.0{ }^{\circ} \mathrm{C}$ to $13.0{ }^{\circ} \mathrm{C}$. The water bath temperature was increased over $26 \mathrm{~d}$ to offset the increasing transpirational cooling of the red cabbage. Low temperatures induce anthocyanin biosynthesis (Whipker et al., 1998). Therefore, for the next $8 \mathrm{~d}$, the walk-in growth chamber temperature and water bath temperature were varied $\left(16.0^{\circ} \mathrm{C}\right.$ to $14.0^{\circ} \mathrm{C}$ and $2.5^{\circ} \mathrm{C}$ to $0.0^{\circ} \mathrm{C}$, respectively) to maintain $10.5{ }^{\circ} \mathrm{C} \pm 1.5{ }^{\circ} \mathrm{C}$ in the labeling chamber. Our objective with the nutrient solution was to provide suitable fertility for initial biomass accumulation (determined by canopy closure) and subsequently to supply limiting nitrogen, which upregulates genes involved in anthocyanin biosynthesis (Peng et al., 2007). Full-strength nutrient solution was supplied at the beginning of labeling and was replaced with full-strength solution 7 and $14 \mathrm{~d}$ later. On days 21 and 28, the nutrient solution was replaced with one-quarterstrength $\left(3.6 \mathrm{mmol} \cdot \mathrm{L}^{-1} \mathrm{~N}\right)$ nutrient solution.

Plants were harvested in dim light $34 \mathrm{~d}$ after being placed in the labeling chamber. Shoots and roots were separated and fresh weights were recorded. All plant tissue was stored at $-80{ }^{\circ} \mathrm{C}$. Shoots to be measured for anthocyanin content were freezedried, ground in a coffee mill to a fine powder, and stored at $-80{ }^{\circ} \mathrm{C}$ until analysis.

Evaluation OF $\mathrm{CO}_{2}$ INCREASE AT START OF EXPERIMENT. After the labeling experiment was completed, a study was conducted to determine the cause of the initial rise in $\mathrm{CO}_{2}$ measured during the first $4 \mathrm{~d}$ of labeling. Unlabeled $\mathrm{CO}_{2}$ concentrations were measured and compared in four situations. First, $\mathrm{CO}_{2}$ was measured for $7 \mathrm{~d}$ in the labeling chamber without the presence of pots, growth medium, or plants. Second, 28 pots containing the same growth medium as during the labeling experiment were incubated for $9 \mathrm{~d}$ at $22^{\circ} \mathrm{C} \pm 1{ }^{\circ} \mathrm{C}$ in constant light with a $P P F$ of $385 \mu \mathrm{mol} \cdot \mathrm{m}^{-2} \cdot \mathrm{s}^{-1}$. No seeds were planted. The pots were then moved into the labeling chamber and $\mathrm{CO}_{2}$ concentration was measured for $4 \mathrm{~d}$, the point at which $\mathrm{CO}_{2}$ concentration returned to its initial value. Third, 'Super Red' red cabbage seeds were planted in growth medium in 28 pots and seedlings were produced as previously. Before moving the pots into the labeling chamber, all seedling shoots were cut and removed, leaving only roots in the growth medium. $\mathrm{CO}_{2}$ concentration was measured for $7 \mathrm{~d}$. Fourth, red cabbage seedlings were grown in the same pots and growth medium. One seedling was selected in each pot; the shoots of all other seedlings were discarded and the roots were left in the growth medium. The pots with intact seedlings were moved into the labeling chamber and $\mathrm{CO}_{2}$ concentration was recorded for $7 \mathrm{~d}$. In each case, the labeling chamber was held at $22.0^{\circ} \mathrm{C} \pm 0.5^{\circ} \mathrm{C}$, was subirrigated daily with full-strength nutrient solution, and the same light conditions as during the labeling experiment were used.

CONFIRMATION OF LABELING OF ANTHOCYANINS. To compare mass spectra of unlabeled anthocyanins with spectra of ${ }^{13} \mathrm{C}$ labeled anthocyanins, 'Super Red' red cabbage was produced in the labeling chamber with similar environmental conditions and using a supply of natural $\mathrm{CO}_{2}\left(98.9 \%{ }^{12} \mathrm{CO}_{2}\right.$ and $1.1 \%$ $\left.{ }^{13} \mathrm{CO}_{2}\right)$. Shoots were harvested, freeze-dried, and ground to a fine powder. Anthocyanins from labeled and unlabeled plant tissue were extracted and analyzed by HPLC-MS/MS as previously described (Charron et al., 2007). Briefly, $0.10 \mathrm{~g}$ of lyophilized tissue was extracted in $10.0 \mathrm{~mL}$ of $10 \%$ formic acid in methanol $(\mathrm{v} / \mathrm{v})$. A $0.75-\mathrm{mL}$ aliquot was filtered through a $0.2-\mu \mathrm{m}$ nylon filter, dried under nitrogen gas, and reconstituted in methanol : 10\% aqueous formic acid ( $1: 9$, by volume). Extracted samples were analyzed on an Agilent Technologies (Palo Alto, CA) series 1100 HPLC with a model SL ion trap spectrophotometer. The column was an Agilent Zorbax StableBond C18 $(150 \times 4.6 \mathrm{~mm}$ i.d., $3.5 \mu \mathrm{m})$. Mobile phase A was $10 \%$ formic acid in water $(\mathrm{v} / \mathrm{v})$ and mobile phase $\mathrm{B}$ was methanol. The solvent gradient was 0 to $20 \mathrm{~min}, 5 \%$ to $15 \%$ $\mathrm{B}$; 20 to $40 \mathrm{~min}, 15 \%$ to $22 \% \mathrm{~B}$; 40 to $55 \mathrm{~min}, 22 \%$ to $30 \% \mathrm{~B} ; 55$ to $80 \mathrm{~min}, 30 \%$ to $35 \% \mathrm{~B} ; 80$ to $85 \mathrm{~min}, 35 \%$ to $100 \% \mathrm{~B} ; 85$ to $90 \mathrm{~min}, 100 \% \mathrm{~B}$; 90 to $95 \mathrm{~min}, 100 \%$ to $5 \% \mathrm{~B}$; 95 to $100 \mathrm{~min}$, $5 \%$ B. Mass spectra of anthocyanins from unlabeled plant tissue were used for compound identification and were compared with mass spectra of anthocyanins from labeled plant tissue to characterize labeled anthocyanins. Authentic standards of cyanidin-3-glucoside (Indofine Chemical Co., Somerville, NJ) and cyanidin 3,5-diglucoside (ChromaDex, Irvine, CA) were used to aid in anthocyanin identifications.

\section{Results and Discussion}

System PERFormance. At harvest, the total shoot fresh weight (FW) of the 28 plants was $1556 \mathrm{~g}$ (mean $\pm \mathrm{SD}=56 \pm$ $12 \mathrm{~g})$ and the total root FW was $491 \mathrm{~g}$ (mean $\pm \mathrm{SD}=18 \pm 5 \mathrm{~g}$ ). The mass flow meter measured $156.8 \mathrm{~L}$ of ${ }^{13} \mathrm{CO}_{2}$ injected into the labeling chamber during growth of the red cabbage.

The temperature in the labeling chamber was successfully maintained at $22{ }^{\circ} \mathrm{C} \pm 1{ }^{\circ} \mathrm{C}$ for $26 \mathrm{~d}$ and at $10.5{ }^{\circ} \mathrm{C} \pm 1.5^{\circ} \mathrm{C}$ for the final $8 \mathrm{~d}$ (Fig. 2A). The heat exchanger prevented condensation on the inside walls of the labeling chamber and was particularly important in removing heat produced by the lamps. This additional cooling capacity was an advantage over a previous system we developed that controlled the temperature of the labeling chamber only by regulating the exterior temperature (Kurilich et al., 2003). The relative humidity 
increased from $65 \%$ to $85 \%$ as a result of the increased transpiration as plant biomass increased during the course of the experiment (Fig. 2B). There was a diurnal rise and fall in relative humidity that corresponded with daily subirrigation. Oxygen concentration increased from $20 \%$ to $29 \%$ (Fig. 2C). The rate of increase was highest at day 21 and decreased thereafter. Atmospheric pressure in the labeling chamber generally tracked the pressure outside of the chamber (data not shown). The continuous production of $\mathrm{O}_{2}$ during the photosynthetic fixation of carbon would have produced a slightly higher pressure inside the labeling chamber relative to the outside, thereby creating a net flow out and minimizing contamination by outside air. This net outflow may have occurred at joints in the chamber or at plumbing connections.

To optimize the labeling of red cabbage anthocyanins with ${ }^{13} \mathrm{C}$, it was important to identify possible sources of unlabeled carbon. The $\mathrm{CO}_{2}$ concentration in the labeling chamber increased significantly on day 26 and corresponded with a brief dark period resulting from a low temperature alarm in the walkin growth chamber that turned off the lights. The $\mathrm{CO}_{2}$ increase likely resulted from the carbohydrate oxidation pathways of dark respiration (Fig. 2D). The $\mathrm{CO}_{2}$ produced would have originated from substrate that had previously incorporated ${ }^{13} \mathrm{C}$ from the ${ }^{13} \mathrm{CO}_{2}$-enriched atmosphere. When light was restored, $\mathrm{CO}_{2}$ levels were rapidly reduced by photosynthetic carbon fixation.

A more problematic event was the $\mathrm{CO}_{2}$ increase measured during the first $43 \mathrm{~h}$ of the experiment. Within $1 \mathrm{~h}$ after the labeling chamber was sealed and the initial volume of ${ }^{13} \mathrm{CO}_{2}$ was injected, a rise in $\mathrm{CO}_{2}$ was observed and the valve of the ${ }^{13} \mathrm{CO}_{2}$ source tank was temporarily closed. The rise in $\mathrm{CO}_{2}$ concentration, which persisted until day 2 , was therefore attributed to natural $\mathrm{CO}_{2}$. Because the IRGA was calibrated for ${ }^{13} \mathrm{CO}_{2}$, the actual increase in natural $\mathrm{CO}_{2}$ was about $25 \%$ of that measured by the IRGA. After correcting for the increased IRGA sensitivity to natural $\mathrm{CO}_{2}$ and accounting for the volume of the labeling chamber (648.9 L), the volume of natural $\mathrm{CO}_{2}$ present on day 2 was calculated to be $0.25 \%$ of the volume of ${ }^{13} \mathrm{CO}_{2}$ injected into the labeling chamber during the experiment. This fraction of natural $\mathrm{CO}_{2}$ would have minimal impact on ${ }^{13} \mathrm{C}$ incorporation into continuously synthesized compounds, but potentially could dilute ${ }^{13} \mathrm{C}$ incorporation of compounds synthesized primarily at the beginning of labeling.

INITIAL $\mathrm{CO}_{2}$ INCREASE. When the labeling chamber was sealed with no pots or growth medium, the $\mathrm{CO}_{2}$ concentration decreased from 559 to $532 \mu \mathrm{L} \cdot \mathrm{L}^{-1}$ over $7 \mathrm{~d}$ (Fig. 3). The presence of pots with growth medium in the labeling chamber resulted in a $\mathrm{CO}_{2}$ increase from 580 to $602 \mu \mathrm{L} \cdot \mathrm{L}^{-1}$ over $42 \mathrm{~h}$, followed by a decrease to $512 \mu \mathrm{L} \cdot \mathrm{L}^{-1}$ on day 4. Although the growth medium is a clay-based material, it
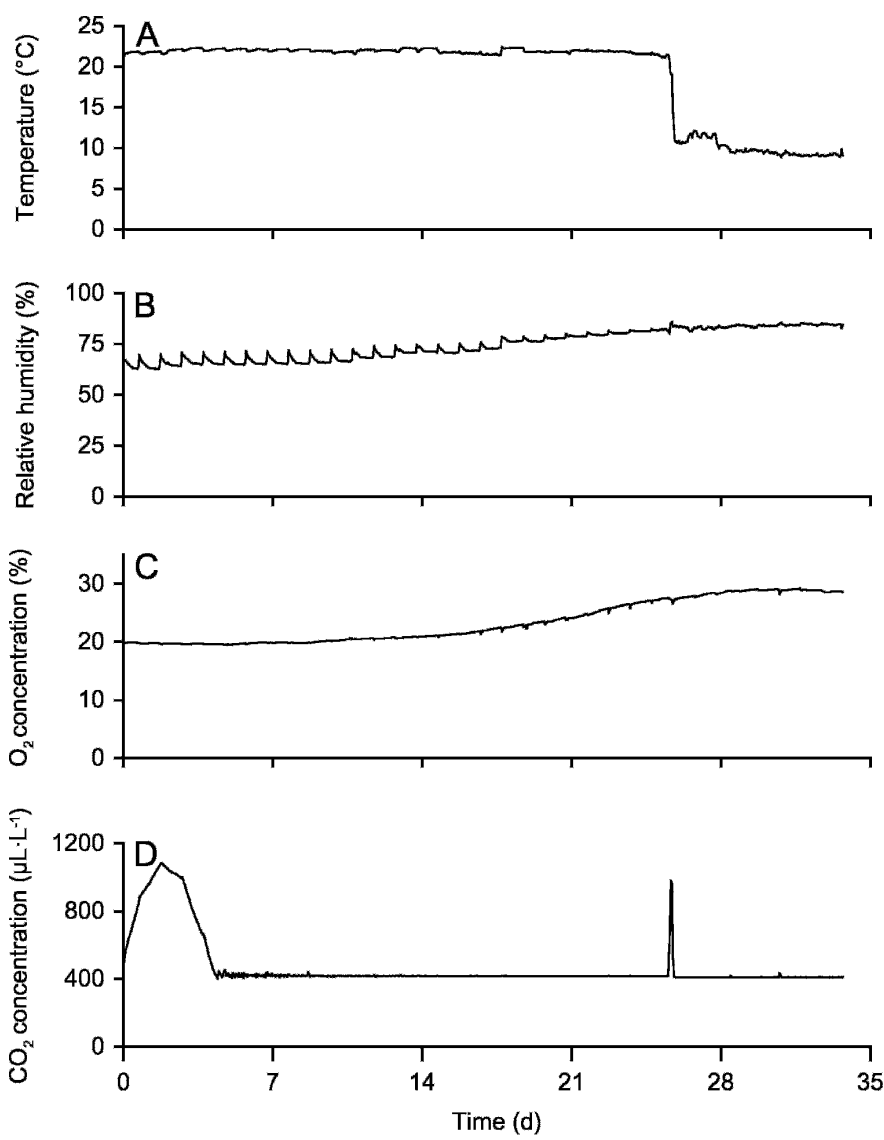

Fig. 2. Environmental conditions in labeling chamber recorded during ${ }^{13} \mathrm{C}$ labeling of red cabbage over $34 \mathrm{~d}$.

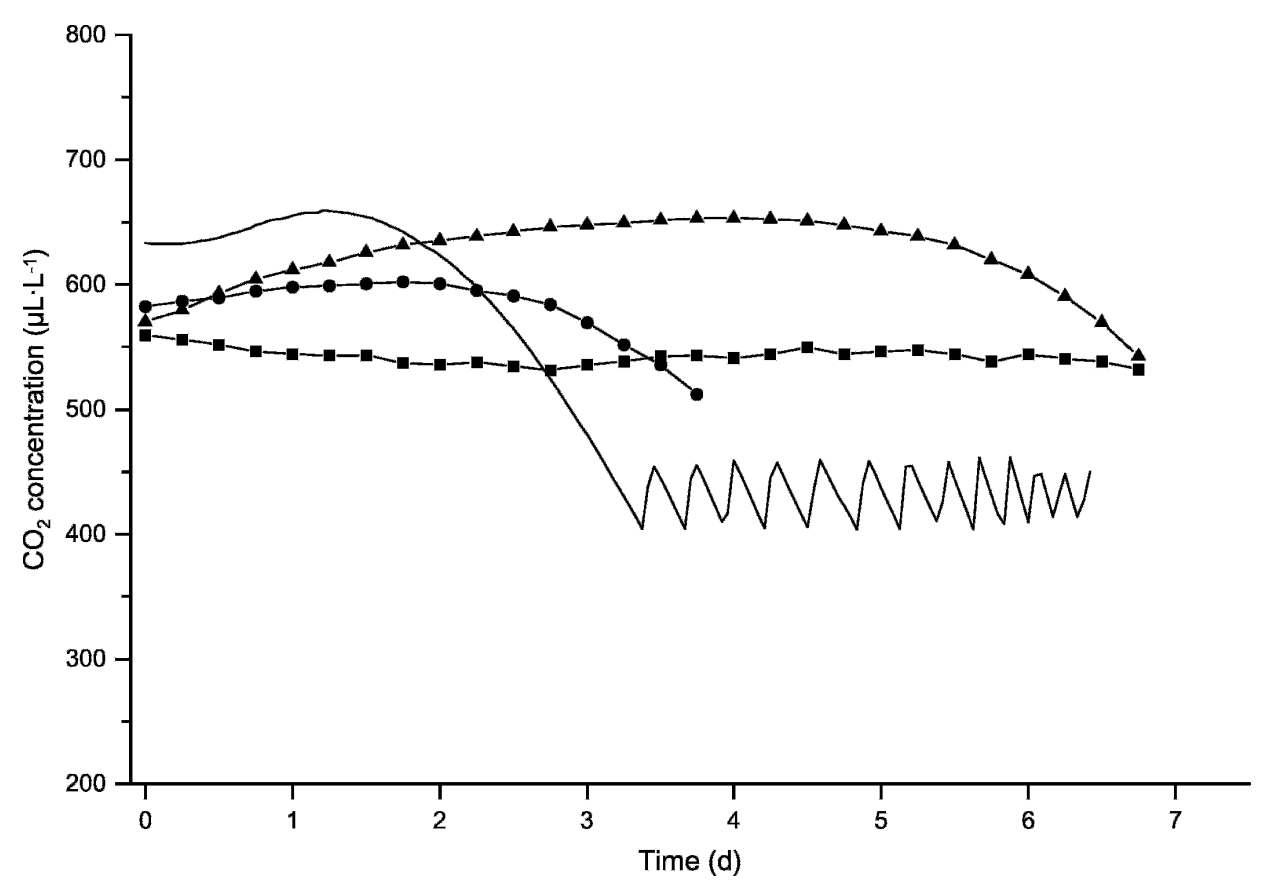

Fig. 3. Carbon dioxide concentration during $7 \mathrm{~d}$ in the labeling chamber under the following conditions: 1) no pots or growth medium $(\boldsymbol{\bullet}), 2)$ pots with growth medium $(\bullet), 3)$ pots with growth medium and cut roots $(\boldsymbol{\Lambda})$, and 4) pots with growth medium, cut roots, and intact seedlings (-). 
may contain sufficient carbon substrate to support microbial metabolism and respiration. Besides the respiratory $\mathrm{CO}_{2}$ from possible microbial activity, the prolonged rise of $\mathrm{CO}_{2}$ in the labeling chamber when pots with growth medium and roots were present indicated that roots left in the growth medium after thinning continued to respire detectable levels of $\mathrm{CO}_{2}$. Respiration of cut roots has been widely documented for freshcut root produce such as radishes (del Aguila et al., 2006). When intact seedlings were placed in the labeling chamber with growth medium and roots of cut seedlings, the $\mathrm{CO}_{2}$ increase from microbial and root respiration was offset by carbon fixation. As shown in Fig. 3, after 3 d, $\mathrm{CO}_{2}$ levels decreased to the set point required for solenoid activation, resulting in the sawtooth pattern reflecting $\mathrm{CO}_{2}$ addition via the solenoid and $\mathrm{CO}_{2}$ removal by photosynthesis.

ANTHOCYANINS IN 'SUPER RED' RED CABBAGE. A growing body of evidence indicates that consuming anthocyanin-rich foods may provide several health benefits, including neuroprotection, amelioration of obesity, protection of cardiovascular health, and disruption of carcinogenic processes (Bell and Gochenaur, 2006; Galli et al., 2006; Jayaprakasam et al., 2006; Shih et al., 2007). These health benefits have fueled interest in anthocyanin identification in various food sources. In this study, anthocyanin identification was based on mass spectra of unlabeled anthocyanins, which were compared with those of labeled anthocyanins with the same HPLC retention times. Structural characterization of previously reported anthocyanins has been described (Charron et al., 2007; McDougall et al., 2007; Wu and Prior, 2005a) and therefore we primarily discuss newly found anthocyanins. Nuclear magnetic resonance data have shown that hexoses of red cabbage anthocyanins consist primarily of diglucose and glucose attached to positions 3 and 5 of cyanidin, respectively, and that aliphatic and aromatic acids commonly are acylated to the glucose residues of position 3 (Idaka et al., 1987a, 1987b; Ikeda et al., 1987). Identifications of newly found anthocyanins were based on these nuclear magnetic resonance data, the determination that MS/MS fragmentation of anthocyanins occurs almost exclusively at the glycosidic bonds between the flavylium ring and adjacent glycosides, and the finding that cleavage of ester linkages between glycosides and acylated groups has not been observed (Giusti et al., 1999). Acylated groups were determined by calculating combinations of aliphatic and aromatic acids commonly found in anthocyanins.

Thirty-seven anthocyanins were detected, including 14 that are reported here for the first time (Fig. 4 and Table 1). The same anthocyanins were present in labeled and unlabeled red cabbage, indicating that the labeling process did not significantly affect anthocyanin biosynthesis. To our knowledge, this is the first study of red cabbage anthocyanins for which the red cabbage cultivar was reported. Cultivar-dependent variation in anthocyanin profiles occur in other horticultural crops and may explain why we found previously unreported anthocyanins (da Silva et al., 2007; Pomar et al., 2005).
Peak numbers are used to represent the anthocyanins listed in Table 1. Cyanidin 3-diglucoside-5-glucoside (peak 5) is one of the predominant nonacylated anthocyanins in red cabbage and is the structure from which most of the acylated anthocyanins are derived (Wu and Prior, 2005a). We found exceptions to this pattern among the newly found anthocyanins. Peak 1 had the same fragmentation pattern as peak 5 , having a dihexose at position 3 of cyanidin and a hexose at position 5. However, peak 1 eluted 6 min earlier than peak 5. Anthocyanins containing a galactose elute sooner than the same anthocyanins with a corresponding glucose (Wu and Prior, 2005b), indicating that peak 1 had one or more galactose residues. There were insufficient data to determine the identities of the hexoses associated with peak 1 . Similarly, peaks 2,7 , and 8 had mass spectra indicating a single hexose at the 3- and 5-positions of cyanidin. Peak 7 was identified as cyanidin 3,5-diglucoside based on comparison of its retention time with that of an authentic standard, but the precise identifications of the hexoses of peaks 2 and 8 could not be determined.

Delphinidin differs from cyanidin by the addition of a hydroxyl group on the anthocyanidin B-ring. Peak 3 was tentatively identified as delphinidin 3-diglucoside-5-glucoside based on its mass spectrum ([M] $]^{+} m / z 789, \mathrm{MS} / \mathrm{MS} m / z 627$ [M-

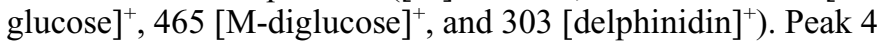
was identified as delphinidin 3,5-diglucoside $\left([\mathrm{M}]^{+} m / z 627\right.$,

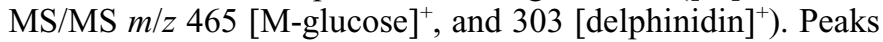
3 and 4 were minor anthocyanins but are noteworthy because delphinidin-based anthocyanins from red cabbage have not been previously reported.

The mass spectra of peak 12 revealed an MS/MS $m / z$ ion of $449[\mathrm{M}-632]^{+}$. The loss of 632 units $(\mathrm{u})$ corresponds to a residue at the cyanidin 3-position of diglucose acylated with caffeic and $p$-coumaric acids $(324+162+146 \mathrm{u})$ or triglucose acylated with $p$-coumaric acid $(486+146 \mathrm{u})$. The ambiguity of the identification of peak 12 arises because glucose and caffeic acid have the same molecular mass. Mass spectra of the ${ }^{13} \mathrm{C}$-labeled anthocyanins are discussed below and indicated that the loss of $632 \mathrm{u}$ from peak 12 likely was triglucose $+p$-coumaric acid. Therefore, peak 12 was tentatively identified as cyanidin 3-( $p$ coumaroyl) triglucoside-5-glucoside. The identifications of peaks 22, 23, and 32 were also initially obscured by the similar molecular masses of glucose and caffeic acid, but were
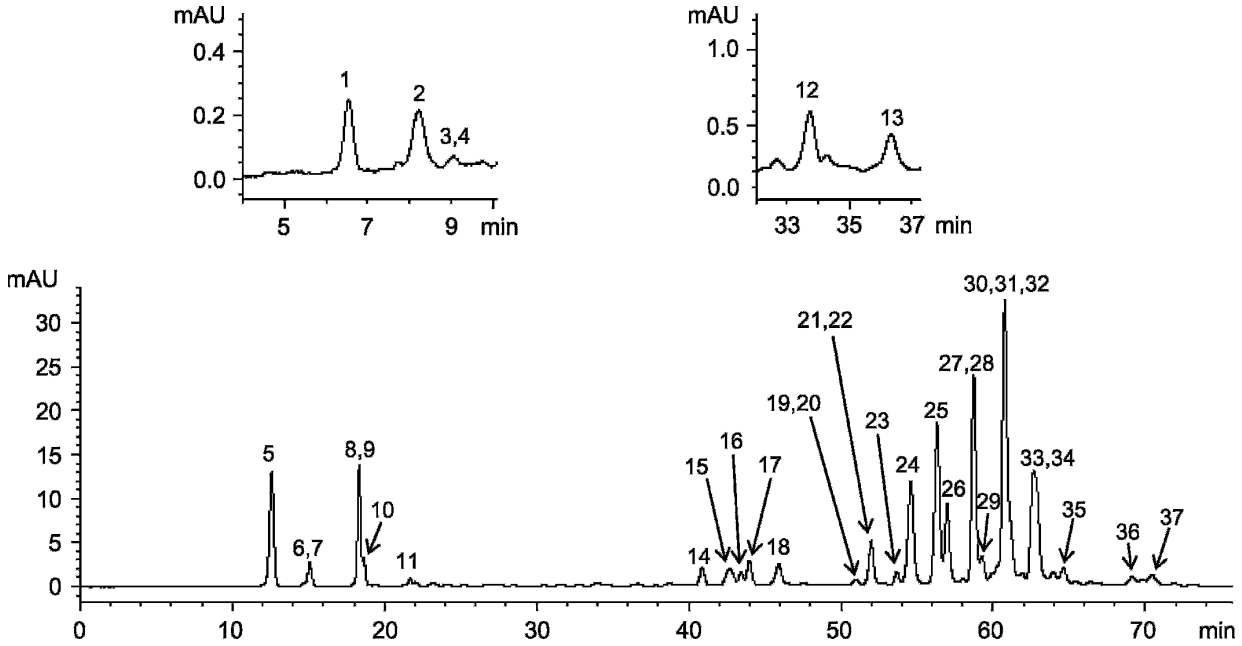

Fig. 4. Reverse-phase high-performance liquid chromatography chromatograms of ${ }^{13} \mathrm{C}$-labeled anthocyanins from 'Super Red' red cabbage. Peak identities are listed in Table 1. 
Table 1. Anthocyanins in unlabeled and ${ }^{13} \mathrm{C}$-labeled 'Super Red' red cabbage. ${ }^{\mathrm{z}}$

\begin{tabular}{|c|c|c|c|c|c|c|c|}
\hline \multirow[b]{2}{*}{ Peak } & \multirow[b]{2}{*}{$\begin{array}{c}t_{\mathrm{R}} \\
(\mathrm{min})\end{array}$} & \multirow[b]{2}{*}{$\begin{array}{c}\text { Carbons } \\
\text { (no.) }\end{array}$} & \multicolumn{2}{|c|}{ Unlabeled } & \multicolumn{2}{|c|}{ Labeled } & \multirow[b]{2}{*}{ Anthocyanin } \\
\hline & & & $\begin{array}{l}\mathrm{M}]+ \\
(\mathrm{m} / \mathrm{z})\end{array}$ & $\begin{array}{c}\mathrm{MS} / \mathrm{MS} \\
(\mathrm{m} / \mathrm{z})\end{array}$ & $\begin{array}{l}{[\mathrm{M}]+} \\
(\mathrm{m} / \mathrm{z})\end{array}$ & $\begin{array}{c}\mathrm{MS} / \mathrm{MS}^{\mathrm{y}} \\
(\mathrm{m} / \mathrm{z})\end{array}$ & \\
\hline 1 & 6.5 & 33 & 773 & $611 / 449 / 287$ & 806 & $638 / 470 / 302$ & cyanidin +1 dihexose +1 hexose \\
\hline 3 & 9.1 & 33 & 789 & $627 / 465 / 303$ & 822 & $653 / 486 / 318$ & delphinidin 3-diglucoside-5-glucoside \\
\hline 4 & 9.1 & 27 & 627 & $465 / 303$ & 654 & $486 / 318$ & delphinidin 3,5-diglucoside \\
\hline 5 & 12.6 & 33 & 773 & $611 / 449 / 287$ & 806 & $638 / 470 / 302$ & cyanidin 3-diglucoside-5-glucoside \\
\hline 7 & 15.1 & 27 & 611 & $449 / 287$ & 638 & $470 / 302$ & cyanidin 3,5 -diglucoside \\
\hline 8 & 18.2 & 27 & 611 & $449 / 287$ & 638 & $470 / 302$ & cyanidin +2 hexoses \\
\hline 9 & 18.3 & 44 & 979 & $817 / 449 / 287$ & 1023 & $855 / 470 / 302$ & cyanidin 3-(sinapoyl)-diglucoside-5-glucoside \\
\hline 10 & 18.6 & 43 & 949 & $787 / 449 / 287$ & 992 & $824 / 470 / 302$ & cyanidin 3-(feruloyl) diglucoside-5-glucoside \\
\hline 11 & 21.7 & 21 & 449 & 287 & 470 & 302 & cyanidin 3 -glucoside \\
\hline 12 & 34.0 & 48 & 1081 & $919 / 449$ & 1129 & $961 / 470$ & cyanidin 3-( $p$-coumaroyl) triglucoside-5-glucoside \\
\hline 17 & 44.0 & 60 & 1317 & $1155 / 449$ & 1377 & $1208 / 470$ & cyanidin 3-(feruloyl)(sinapoyl) triglucoside-5-glucoside \\
\hline 18 & 45.9 & 42 & 935 & $773 / 449 / 287$ & 977 & $809 / 470 / 302$ & cyanidin 3-(caffeoyl) diglucoside-5-glucoside \\
\hline 19 & 51.0 & 38 & 817 & $655 / 449 / 287$ & 855 & $687 / 470 / 302$ & cyanidin 3-(sinapoyl) glucoside-5-glucoside \\
\hline 20 & 51.0 & 37 & 787 & $625 / 449 / 287$ & 824 & $656 / 470 / 302$ & cyanidin + hexose + pentose + sinapoyl \\
\hline 21 & 51.9 & 37 & 787 & $625 / 449 / 287$ & 824 & $656 / 470 / 302$ & cyanidin + hexose + pentose + sinapoyl \\
\hline 22 & 51.9 & 53 & 1141 & 979/449 & 1194 & $1026 / 470$ & cyanidin 3-(caffeoyl)(sinapoyl) diglucoside-5-glucoside \\
\hline 23 & 53.6 & 52 & 1111 & 949/449 & 1163 & $995 / 470$ & cyanidin 3-(caffeoyl)(feruloyl) diglucoside-5-glucoside \\
\hline 24 & 54.5 & 42 & 919 & $757 / 449 / 287$ & 961 & $793 / 470 / 302$ & cyanidin 3-(p-coumaroyl) diglucoside-5-glucoside \\
\hline 25 & 56.3 & 43 & 949 & $787 / 449 / 287$ & 992 & $824 / 470 / 302$ & cyanidin 3-(feruloyl) diglucoside-5-glucoside \\
\hline 26 & 56.9 & 44 & 979 & $817 / 449 / 287$ & 1023 & $855 / 470 / 302$ & cyanidin 3-(sinapoyl) diglucoside-5-glucoside \\
\hline 27 & 58.7 & 53 & 1125 & $963 / 449$ & 1178 & $1010 / 470$ & cyanidin 3-(diacyl) diglucoside-5-glucoside \\
\hline 35 & 64.6 & 54 & 1155 & $993 / 449$ & 1209 & $1040 / 470$ & cyanidin 3-(feruloyl)(sinapoyl) diglucoside-5-glucoside \\
\hline 36 & 69.1 & 32 & 655 & 287 & 687 & 302 & cyanidin $3-($ sinapoyl) glucoside \\
\hline 37 & 70.4 & 31 & 625 & 287 & 656 & 302 & cyanidin 3-(feruloyl) glucoside \\
\hline
\end{tabular}

${ }^{\mathrm{z}}$ Anthocyanins in bold reported for first time in red cabbage.

${ }^{\mathrm{y}}$ Tandem mass spectrometry.

facilitated by examination of the mass spectra of their ${ }^{13} \mathrm{C}$ labeled analogs. These compounds consisted of the cyanidin 3-diglucoside-5-glucoside backbone with two groups acylated to the diglucoside. Peaks 23 and 32 were isomers tentatively identified as cyanidin 3-(caffeoyl)(feruloyl) diglucoside-5-glucoside. Peak 22 was identified as cyanidin 3-(caffeoyl)(sinapoyl) diglucoside-5-glucoside. Peak 31 , identified as cyanidin 3 -( $p$-coumaroyl)(feruloyl) diglucoside-5-glucoside, had the same backbone as peaks 22,23 , and 32 , but in contrast to these compounds, neither acyl group was caffeic acid.

Peaks 16, 27, and 34 were isomers with $[\mathrm{M}]^{+} \mathrm{m} / z$ 1125, MS/ MS $m / z 963[\mathrm{M} \text { - glucose }]^{+}$, and $449[\mathrm{M} \text { - diglucose }-352]^{+}$. The residue consisting of $352 \mathrm{u}$ could be two ferulic acids $(176+$ $176 u)$ or one $p$-coumaric and one sinapic acid $(146+206 u)$. The HPLC retention times of peaks 16, 27, and 34 were 43.4, 58.7 , and $62.8 \mathrm{~min}$, respectively, indicated a range of hydro- phobicities but did not aid in conclusively identifying the two acylated groups for any of these peaks.

Peaks 20,21 , and 28 had $[\mathrm{M}]^{+} \mathrm{m} / z 787$ yielding MS/MS ions

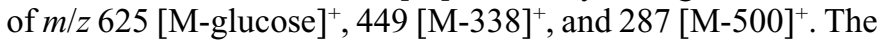
loss of $338 \mathrm{u}$ could be explained by the loss of a hexose attached to ferulic acid $(162+176 \mathrm{u})$ or the loss of a pentose attached to sinapic acid $(132+206 \mathrm{u})$. The loss likely consisted of a pentose + sinapic acid, as supported by mass spectral analysis of the ${ }^{13} \mathrm{C}$-labeled anthocyanins. The exact identification of the pentose could not be determined, although xylose has been previously found in red cabbage anthocyanins (Charron et al., 2007; Wu and Prior, 2005a). The different retention times of peaks 20,21 , and 28 probably resulted from different sites of attachment of the sinapic acid and/or the identity of the pentose. Wu and Prior (2005b) used a similar HPLC-MS/MS method to study fruit and berry anthocyanins and reported that cyanidin 
3-arabinoside eluted shortly after cyanidin 3-glucoside and that cyanidin 3-xyloside eluted much after both compounds. However, it is not possible to apply these retention data to identify the pentose(s) in our study because the retention times likely were affected significantly by the sinapic acid residue.

Peak $36\left([\mathrm{M}]^{+} m / z 655\right)$ had a single fragment, $\mathrm{m} / \mathrm{z} 287$ [cyanidin] ${ }^{+}$, corresponding to a loss of glucose + sinapic acid, and was identified as cyanidin 3-(sinapoyl) glucoside. Peak 37 was structurally similar to peak 36 , differing only by the substitution of ferulic acid for sinapic acid, and was identified as cyanidin 3-(feruloyl) glucoside.

Characterization of ${ }^{13} \mathrm{C}$ LABELED ANTHOCYANINS. Incorporation of ${ }^{13} \mathrm{C}$ into anthocyanins of red cabbage grown in ${ }^{13} \mathrm{CO}_{2}$ was confirmed by mass shifts in the $[\mathrm{M}]^{+} \mathrm{m} / z$ and MS/MS $m / z$ data in Table 1. For example, in unlabeled red cabbage, cyanidin 3-diglucoside-5-glucoside (peak 5) has 33 carbons and had $[\mathrm{M}]^{+} m / z 773$ (Fig. 5A). In labeled red cabbage, cyanidin 3-diglucoside-5-glucoside has the same number of carbons but had [M] $]^{+} m / z 806$ due to a shift of $33 \mathrm{u}$ resulting from the $33{ }^{13} \mathrm{C}$-labeled carbons (Fig. 5B). Although $[\mathrm{M}]^{+} m / z \quad 806$ was the ion of highest intensity for peak 5 in labeled red cabbage, other ions were present as well, representing molecules with incomplete incorporation of ${ }^{13} \mathrm{C}$. For example, $[\mathrm{M}]^{+} \mathrm{m} / \mathrm{z}$ 805 could result from the incorporation of $32{ }^{13} \mathrm{C}$ and $1{ }^{12} \mathrm{C}$. Mass shifts caused by the assimilation of ${ }^{13} \mathrm{C}$ were also evident in fragment ions. The MS/MS ions of unlabeled peak 5 were $m / z 611$ [M-glucose] $]^{+}$,

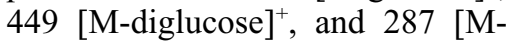
glucose-diglucose $]^{+}$(Fig. 5C). In contrast, the analogous ions for peak 5 in labeled red cabbage were $\mathrm{m} / \mathrm{z} 638$ [M-glucose] $]^{+}, 470$ [Mdiglucose $]^{+}$, and 302 [M-glucosediglucose $]^{+}$(Fig. 5D). These ions differ from those of unlabeled peak 5 because in labeled peak $5,{ }^{13} \mathrm{C}$ was incorporated into the six carbon positions of each glucose.

The mass spectra of unlabeled anthocyanins provided sufficient data to identify most of the anthocyanins. Furthermore, the predominant molecular ion in the mass spectra of the ${ }^{13} \mathrm{C}$-labeled analogs of identified anthocyanins corresponded with incorporation of ${ }^{13} \mathrm{C}$ into all carbon positions. As a
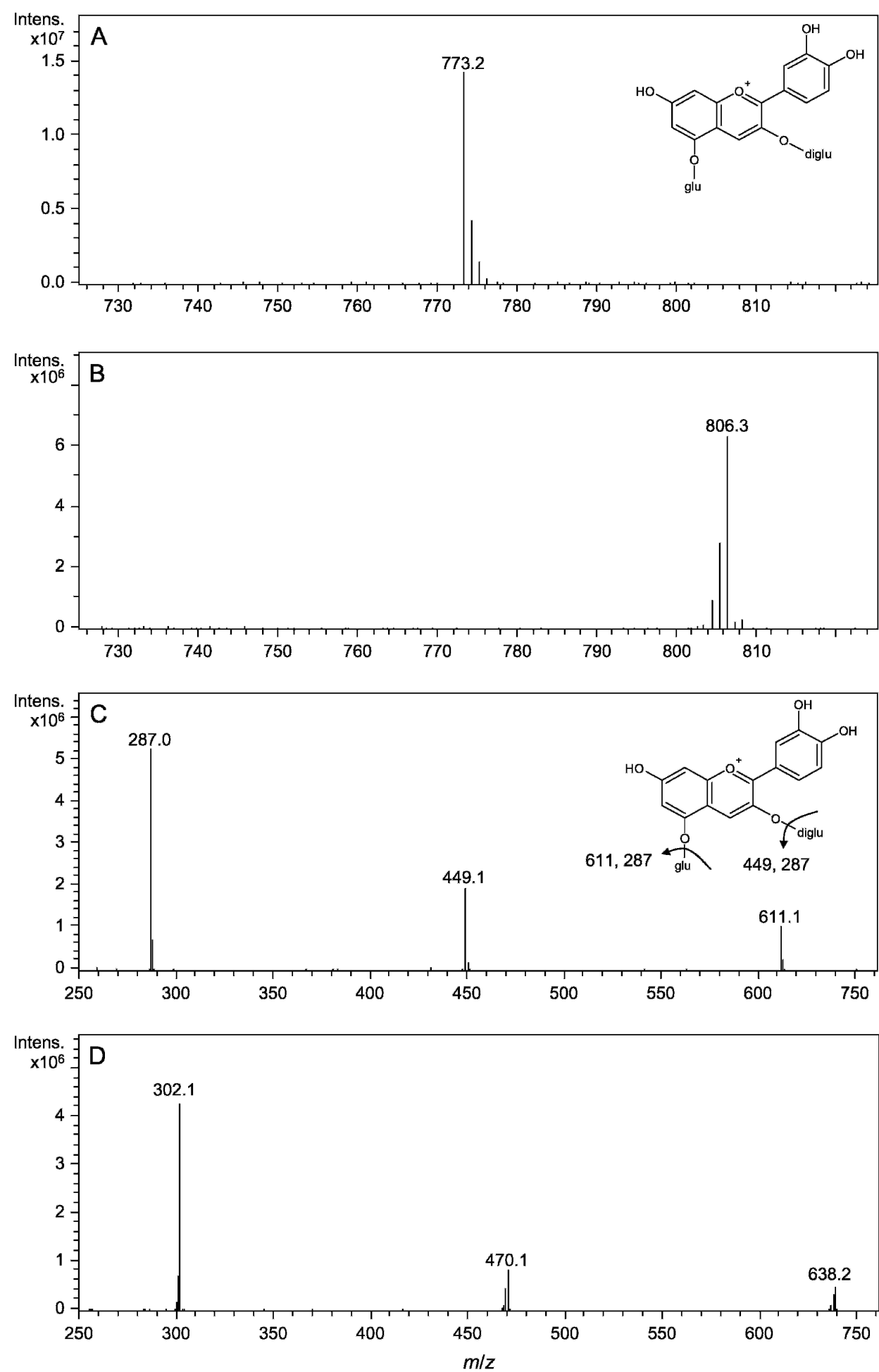

Fig. 5. Mass spectra of unlabeled and ${ }^{13} \mathrm{C}$-labeled cyanidin 3-diglucoside-5-glucoside (cy 3-diglu-5-glu). (A) Structure and [M] ${ }^{+} \mathrm{m} / \mathrm{z}$ for unlabeled cy 3-diglu-5-glu. (B) $[\mathrm{M}]^{+} \mathrm{m} / \mathrm{z}$ for ${ }^{13} \mathrm{C}$-labeled cy 3-diglu-5-glu. (C) MS/MS $\mathrm{m} / \mathrm{z}$ fragments of unlabeled cy 3-diglu-5-glu. (D) MS/MS $\mathrm{m} / \mathrm{z}$ fragments of ${ }^{13} \mathrm{C}$-labeled cy 3-diglu-5-glu.

consequence of the predominance of completely labeled molecules, the mass spectra of ${ }^{13} \mathrm{C}$-labeled anthocyanins provided unique information that aided in identifying anthocyanins that could not be identified by their mass spectra when unlabeled. The sum of the number of carbons in each moiety 
of an anthocyanin is equivalent to the nominal mass shift in the labeled anthocyanin. This result occurs because each ${ }^{13} \mathrm{C}$ contributes an additional $1 \mathrm{u}$ to the mass of a molecule compared with the mass of an unlabeled molecule. Peak 12 had $[\mathrm{M}]^{+} m / z 1081$ when unlabeled and $[\mathrm{M}]^{+} m / z 1129$ when labeled, a mass shift of $48 \mathrm{u}$. Therefore, peak 12 had a total of 48 carbons. The MS/MS $m / z$ ion 449 [M-632] $^{+}$is consistent with the presence of cyanidin, which has 15 carbons, and a glucose at the 5-position, which has 6 carbons. Together, these moieties account for 21 of the $48 \mathrm{u}$ of the $[\mathrm{M}]^{+} \mathrm{m} / \mathrm{z}$ mass shift observed in the labeled compound. The residue at the 3 -position would be predicted to account for the remaining $27 \mathrm{u}$. The molecular mass of this residue $(632 \mathrm{u})$ when unlabeled is consistent with diglucose acylated with caffeic and $p$-coumaric acids $(324+$ $162+146 \mathrm{u})$ or triglucose acylated with $p$-coumaric acid $(486+$ $146 \mathrm{u})$. However, triglucose (18 carbons) $+p$-coumaric acid (9 carbons) would contribute the expected remaining $27 \mathrm{u}$ to the mass shift of $48 \mathrm{u}$, whereas diglucose (12 carbons) + caffeic acid ( 9 carbons) + p-coumaric acid ( 9 carbons) would contribute $30 \mathrm{u}$. Therefore, the mass spectra of ${ }^{13} \mathrm{C}$-labeled peak 12 supported the identification of peak 12 as cyanidin $3-(p-$ coumaroyl) triglucoside-5-glucoside. Similar comparisons of carbon number and $[\mathrm{M}]^{+} \mathrm{m} / \mathrm{z}$ mass shift in ${ }^{13} \mathrm{C}$-labeled anthocyanins were used to help identify peaks 20 through 23,28 , and 32. However, consideration of carbon number and mass shift did not provide insight into the structures of the isomeric peaks 16,27 , and 34. These peaks had a residue that could consist of two ferulic acids or one $p$-coumaric and one sinapic acid. Both possible residues contain the same number of carbons (20) and therefore would contribute the same amount $(20 \mathrm{u})$ to the $[\mathrm{M}]^{+} m / z$ mass shift when ${ }^{13} \mathrm{C}$-labeled. Thus, it is not possible to distinguish between the two residues based on the mass spectra of the labeled anthocyanins.

In conclusion, we labeled red cabbage grown in a controlled environment with atmospheric ${ }^{13} \mathrm{CO}_{2}$ and characterized 37 labeled and unlabeled anthocyanins by HPLC-MS/MS. Incorporation of ${ }^{13} \mathrm{C}$ into anthocyanins provided insights useful for the elucidation of anthocyanin structure. This labeling system could be used for isotopic labeling of other crops that could be grown hydroponically. Although we labeled continuously from seedling stage to harvest, this system could also be used for pulse-labeling to produce photosynthate that could be traced through metabolic processes after brief exposures to ${ }^{13} \mathrm{CO}_{2}$. The fact that ${ }^{13} \mathrm{C}$ is a stable isotope is a particular benefit because crops grown in this labeling system would be suitable for human nutrition studies that evaluate bioavailability of potentially healthful plant compounds.

\section{Literature Cited}

Bell, D.R. and K. Gochenaur. 2006. Direct vasoactive and vasoprotective properties of anthocyanin rich extracts. J. Appl. Physiol. 100:1164-1170.

Charron, C.S., B.A. Clevidence, S.J. Britz, and J.A. Novotny. 2007. Effect of dose size on bioavailability of acylated and nonacylated anthocyanins from red cabbage (Brassica oleracea L. var. capitata). J. Agr. Food Chem. 55:5354-5362.

da Silva, F.L., M.T. Escribano-Bailón, J.J. Pérez Alonso, J.C. RivasGonzalo, and C. Santos-Buelga. 2007. Anthocyanin pigments in strawberry. LWT-Food Sci. Technol. 40:374-382.

del Aguila, J.S., F.F. Sasaki, L.S. Heiffig, E.M.M. Ortega, A.P. Jacomino, and R.A. Kluge. 2006. Fresh-cut radish using different cut types and storage temperatures. Postharvest Biol. Technol. 40:149-154.
Galli, R.L., D.F. Bielinski, A. Szprengiel, B. Shukitt-Hale, and J.A. Joseph. 2006. Blueberry-supplemented diet reverses age-related decline in hippocampal HSP70 neuroprotection. Neurobiol. Aging 27:344-350.

Giusti, M.M., L.E. Rodriguez-Saona, D. Griffin, and R.E. Wrolstad. 1999. Electrospray and tandem mass spectroscopy as tools for anthocyanin characterization. J. Agr. Food Chem. 47:4657-4664.

Grusak, M.A. 1997. Intrinsic stable isotope labeling of plants for nutritional investigations in humans. J. Nutr. Biochem. 8:164-171.

Haupt-Herting, S., K. Klug, and H.P. Fock. 2001. A new approach to measure gross $\mathrm{CO}_{2}$ fluxes in leaves. Gross $\mathrm{CO}_{2}$ assimilation, photorespiration, and mitochondrial respiration in the light in tomato under drought stress. Plant Physiol. 126:388-396.

Idaka, E., K. Suzuki, H. Yamakita, T. Ogawa, T. Kondo, and T. Goto. 1987a. Structure of monoacylated anthocyanins isolated from red cabbage, Brassica oleracea. Chem. Lett. (Jpn.) 1:145-148.

Idaka, E., H. Yamakita, T. Ogawa, T. Kondo, M. Yamamoto, and T. Goto. 1987b. Structure of 3 diacylated anthocyanins isolated from red cabbage, Brassica oleracea. Chem. Lett. (Jpn.) 6:1213-1216.

Ikeda, K., H. Kikuzaki, M. Nakamura, and N. Nakatani. 1987. Structure of two acylated anthocyanins from red cabbage (Brassica oleracea). Chem. Express 2:563-566.

Jayaprakasam, B., L.K. Olson, R.E. Schutzki, M.-H. Tai, and M.G. Nair. 2006. Amelioration of obesity and glucose intolerance in highfat-fed C57BL/6 mice by anthocyanins and ursolic acid in Cornelian cherry (Cornus mas). J. Agr. Food Chem. 54:243-248.

Kahlon, T.S. and F.I. Chow. 1989. A comparison of methods for the intrinsic labeling of wheat protein with ${ }^{35} \mathrm{~S}$. J. Agr. Food Chem. 37:116-118.

Kollman, V.H., J.L. Hanners, J.Y. Hutson, T.W. Whaley, D.G. Ott, and C.T. Gregg. 1973. Large-scale photosynthetic production of carbon13 labeled sugars: The tobacco leaf system. Biochem. Biophys. Res. Commun. 50:826-831.

Kurilich, A.C., S.J. Britz, B.A. Clevidence, and J.A. Novotny. 2003. Isotopic labeling and LC-APCI-MS quantification for investigating absorption of carotenoids and phylloquinone from kale (Brassica oleracea). J. Agr. Food Chem. 51:4877-4883.

Ma, B.L., K.D. Subedi, and L.M. Dwyer. 2006. Timing and method of ${ }^{12}$ nitrogen-labeled fertilizer application on grain protein and nitrogen use efficiency of spring wheat. J. Plant Nutr. 29:469-483.

McDougall, G.J., S. Fyffe, P. Dobson, and D. Stewart. 2007. Anthocyanins from red cabbage: Stability to simulated gastrointestinal digestion. Phytochemistry 68:1285-1294.

Menino, M.R., C. Carranca, and A. De Varennes. 2007. Distribution and remobilization of nitrogen in young non-bearing orange trees grown under Mediterranean conditions. J. Plant Nutr. 29:1083-1096.

Nogués, S., G. Tcherkez, G. Cornic, and J. Ghashghaie. 2004. Respiratory carbon metabolism following illumination in intact french bean leaves using ${ }^{13} \mathrm{C} /{ }^{12} \mathrm{C}$ isotope labeling. Plant Physiol. 136:3245-3254.

Novotny, J.A., S. Britz, F. Caulfield, G. Beecher, and B. Clevidence. 2003. Intrinsic labeling of plants for bioavailability studies, p. 131138. In: J.A. Novotny, M.H. Green, and R.C. Boston (eds.). Mathematical modeling in nutrition and the health sciences. Advances in experimental medicine and biology. Kluwer Academic/ Plenum Publishers, New York.

Peng, M., Y.M. Bi, T. Zhu, and S.J. Rothstein. 2007. Genome-wide analysis of Arabidopsis responsive transcriptome to nitrogen limitation and its regulation by the ubiquitin ligase gene NLA. Plant Mol. Biol. 65:775-797.

Pomar, F., M. Novo, and A. Masa. 2005. Varietal differences among the anthocyanin profiles of 50 red table grape cultivars studied by high performance liquid chromatography. J. Chromatogr. A. 1094:34-41.

Robinson, J.M. 1984. Photosynthetic carbon metabolism in leaves and isolated chloroplasts from spinach plants grown under short and intermediate photosynthetic periods. Plant Physiol. 75:397409. 
Schiltz, S., N. Munier-Jolain, C. Jeudy, J. Burstin, and C. Salon. 2005. Dynamics of exogenous nitrogen partitioning and nitrogen remobilization from vegetative organs in pea revealed by ${ }^{15} \mathrm{~N}$ in vivo labeling throughout seed filling. Plant Physiol. 137:14631473.

Shih, P.-H., C.-T. Yeh, and G.-C. Yen. 2007. Anthocyanins induce the activation of phase II enzymes through the antioxidant response element pathway against oxidative stress-induced apoptosis. J. Agr. Food Chem. 55:9427-9435.

Sun, J., T.W. Okita, and G.E. Edwards. 1999. Modification of carbon partitioning, photosynthetic capacity, and $\mathrm{O}_{2}$ sensitivity in Arabidopsis plants with low ADP-glucose pyrophosphorylase activity. Plant Physiol. 119:267-276.

Talhelm, A.F., S.A. Qadir, M.D. Powers, K.L. Bradley, A.L. Friend, and K.S. Pregitzer. 2007. ${ }^{13} \mathrm{C}$ labeling of plant assimilates using a simple canopy-scale open air system. Plant Soil 296:227-234.
Whipker, B.E., J.L. Gibson, R.A. Cloyd, C.R. Campbell, and R. Jones. 1998. Success with ornamental cabbage and kale. North Carolina Coop. Ext. Serv. Hort. Info. Lfit. 507:1-9.

$\mathrm{Wu}, \mathrm{X}$. and R.L. Prior. 2005a. Identification and characterization of anthocyanins by high-performance liquid chromatography-electrospray ionization-tandem mass spectrometry in common foods in the United States: Vegetables, nuts, and grains. J. Agr. Food Chem. 53:3101-3113.

$\mathrm{Wu}, \mathrm{X}$. and R.L. Prior. 2005b. Systematic identification and characterization of anthocyanins by HPLC-ESI-MS/MS in common foods in the United States: Fruits and berries. J. Agr. Food Chem. 53:25892599.

Yamagata, M., H. Kouchi, and T. Yoneyama. 1987. Partitioning and utilization of photosynthate produced at different growth stages after anthesis in soybean (Glycine max L. Merr.): Analysis by longterm 13C-labelling experiments. J. Expt. Bot. 38:1247-1259. 